\title{
Compensatory Changes in Contralateral Sympathetic Neurons of the Superior Cervical Ganglion and in their Terminals in the Pineal Gland Following Unilateral Ganglionectomy ${ }^{1}$
}

\author{
MENASHE DORNAY, VARDA H. GILAD, AND GAD M. GILAD ${ }^{2}$ \\ The Center for Neuroscience and Behavioral Research and Department of Isolope Research, The Weizmann Institute of Science, \\ 76100 Rehovot, Israel
}

\begin{abstract}
The sympathetic noradrenergic neurons of the rat superior cervical ganglia (SCGs) provide the major source of innervation to the pineal gland. The present study sought to determine $(1)$ if this sympathetic innervation can undergo collateral sprouting following partial denervation of the pineal by unilateral removal of the SCG (ganglionectomy), and (2) whether such growth of axon terminals is associated with biochemical changes in the contralateral SCG. In the pineal gland following partial denervation, residual noradrenergic terminals underwent compensatory changes indicative of collateral sprouting, as evidenced by: (1) a rapid reduction in tyrosine hydroxylase (TH) activity and in [ $\left.{ }^{3} \mathrm{H}\right]$ norepinephrine (NE) uptake, to about $50 \%$ of control by 2 days, which was followed by a gradual but sustained increase to levels of approximately $80 \%$ of control by 10 days and (2) a reduction in the intensity and density but not in the distribution of fibers containing NE-induced fluorescence by 2 days, which was followed by a sustained increase. In the contralateral SCG, choline acetyltransferase (CAT) activity, a marker of cholinergic preganglionic terminals, was transiently increased to about $115 \%$ of control by 4 days and returned to control levels by 14 days after unilateral ganglionectomy; later, TH activity in noradrenergic cell bodies was gradually increased to about $140 \%$ of control by 10 days where it remained for up to $\mathbf{5 2}$ days. Unilteral ganglionectomy combined with decentralization of the contralateral SCG by preganglionic nerve cut prevented the compensatory changes in noradrenergic nerve terminals within the pineal. We conclude: (1) following partial denervation of the pineal gland by unilateral ganglionectomy, residual noradrenergic terminals undergo compensatory collateral sprouting; (2) after unilateral ganglionectomy, changes in the pineal are preceded by sequential enhancement, first of CAT activity in cholinergic preganglionic terminals and then of TH activity within noradrenergic nerve cell bodies of the contralateral SCG; and (3) the presence of intact preganglionic innervation is essential for the expression of the compensatory collateral sprouting.
\end{abstract}

Received September 4, 1984; Revised January 15, 1985;

Accepted January 16, 1985

\footnotetext{
${ }^{t}$ This work was supported by grants from the Muscular Dystrophy Association and from the Herman Goldman Foundation. G. M. G. is an incumbent of the Paul and Gabriella Rosenbaum Career Development Chair in perpetuity, established by Paul and Gabriella Rosenbaum Foundation, Chicago, II.

${ }^{2}$ To whom correspondence should be addressed.
}

It is well established that axon terminals which remain intact after partial denervation of a muscle can grow new branches to occupy sites left vacant after degeneration of the lesioned axons (Edds, 1953). Such compensatory collateral sprouting can also occur in sympathetic ganglia (Guth and Bernstein, 1961; Maehlen and Njå, 1982). It has been recently demonstrated that the sympathetic neurons of the superior cervical ganglion (SCG) can undergo heterotypic collateral sprouting in response to a selective partial denervation of a foreign target region in the brain (Loy and Moore, 1977; Stenevi and Björklund, 1978; Crutcher et al., 1979). At present, however, only a few studies have attempted to characterize the reaction of the parent nerve cell bodies during collateral sprouting of their terminal axons (Gilad and Reis, 1979). Lesions of postganglionic sympathetic axons will elicit marked metabolic changes in thcir parent nerve ccll bodies, some of which are closely related to the regenerative growth of the cut axons (Gilad and Gilad, 1983). Although collateral sprouting, like regeneration, represents a similar condition of growth of new axon fibers, the cell body response may be different due to the fact that intact neurons undergoing collateral sprouting have to maintain routine neurotransmission, while in injured neurons this function is largely or wholy impaired (Gilad and Reis, 1979).

In the present study, we chose the sympathetic innervation of the pineal gland which arises from nerve cell bodies in the right and left SCGs (Kappers, 1960; Zieher and Pellegrino de Iraldi, 1966) as a model system. This system is easily accessible and permits the making of reproducible lesions, and its neurochemistry is well characterized. We have investigated the changes in residual noradrenergic terminals within the pineal gland which are elicited by partial denervation after unilateral removal of the SCG. We shall demonstrate by biochemical and histochemical techniques that the residual noradrenergic terminals undergo compensatory changes indicative of homotypic collateral sprouting, and that these responses are associated with changes in parent nerve cell bodies of the SCG, which are different from those associated with axonal injury. Furthermore, intact preganglionic input to the SCG is probably essential for these compensatory changes.

\section{Materials and Methods}

\section{Animals}

Experiments were performed on male Sprague-Dawley rats (Experimental Animals Center, Weizmann Institute of Science, Rehovot, Israel) 2 to 3 months old. They were housed five to a cage, supplied freely with food and water, and maintained at $25^{\circ} \mathrm{C}$ with a 12 -hr light-dark cycle (light $06: 00$ to 18:00 hr).

\section{Surgery}

Rats were operated on while under halothane $\left(2 \%\right.$ in $\left.100 \% \mathrm{O}_{2}\right)$ anesthesia. The SCG and its preganglionic afferent and postganglionic efferent nerves 
were exposed through an incision in the neck (Gilad et al., 1980). Three types of operations were performed: (1) postganglionic nerve crush (axotomy) - the internal carotid nerve was crushed with microdissecting tweezers at an average distance of $5 \mathrm{~mm}$ from the point of its emergence from the ganglion; (2) preganglionic nerve cut (decentralization)-at an average distance of $5 \mathrm{~mm}$ caudal to the ganglion; and (3) ganglionectomy-the SCG was removed after cutting its afferent and efferent nerves. The wound was closed with stainless steel wound clips. Unoperated rats served as controls.

At various times after surgery, rats were decapitated, and the SCG and pineal gland were rapidly removed. Tissues were either freshly used or frozen immediately on dry ice and stored at $-70^{\circ} \mathrm{C}$ for subsequent biochemical assays.

\section{Biochemical methods}

Enzyme assays. One SCG or two pineal glands were homogenized with a glass homogenizer in 0.1 or $0.075 \mathrm{ml}$, respectively, of ice-cold $5 \mathrm{~mm}$ sodium phosphate buffer, $\mathrm{pH} 7.4$, containing $0.1 \%$ Triton $\mathrm{X}-100(\mathrm{v} / \mathrm{v})$.

Tyrosine hydroxylase (TH) activity was assayed by a modification of the method of Coyle (1972). An aliquot $(75 \mu l)$ of tissue homogenate was incubatcd for $30 \mathrm{~min}$ at $37^{\circ} \mathrm{C}$ with $25 \mu \mathrm{l}$ of reaction mixture containing 2.5

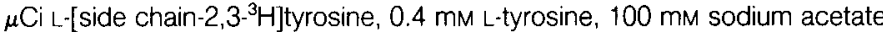
butfer, $\mathrm{pH} 5.8,1.2 \mathrm{~mm}$ 6-methyl-5,6,7,8-tetrahydropterine in $28 \mathrm{~mm}$ mercaptoeihanol, 1300 unils of calalase, and $5 \mathrm{~mm}$ of ferrous sulfate. Under these assay conditions, the activity measured, following isolation of $\left[{ }^{3} \mathrm{H}\right] \mathrm{DOPA}$ formed on activated alumina columns, was linear up to $30 \mathrm{~min}$ with 0.1 to $0.5 \mathrm{mg}$ proteins. In order to detect low levels of TH activity in the pineal gland, only radioactive substrate-2.5 $\mu \mathrm{Ci}(2.2 . \mu \mathrm{M})$ of $\left[{ }^{3} \mathrm{H}\right]$ tyrosine-was used, thus increasing its specific activity.

Choline acetyltransferase (CAT) activity was assayed by the method of Fonnum (1969) with analysis of the acetylcholine formed on Dowex columns as described by Kobayashi et al. (1975).

Uptake of $\left[{ }^{3} \mathrm{H}\right]$ norepinephrine. Immediately after dissections, two pineal glands were homogenized in $0.075 \mathrm{ml}$ of ice-cold $0.32 \mathrm{M}$ sucrose in a glass homogenizer fitted with a Teflon pestle. A $0.05-\mathrm{ml}$ aliquot was added to 0.95 $\mathrm{ml}$ of ice-cold modified Krebs-Ringer phosphate buffer, pH 7.4 (Heikkila et al., 1975), containing $7.7 \times 10^{-8} \mathrm{M}\left[{ }^{3} \mathrm{H}\right]$ norepinephrine (NE) (specific activity, $12.4 \mathrm{Ci} / \mathrm{mmol}$; New England Nuclear). After $10 \mathrm{~min}$ of incubation at $37^{\circ} \mathrm{C}$, the reaction was stopped by addition of $3.5 \mathrm{ml}$ of ice-cold Krebs-Ringer buffer, and the mixture was centrifuged at $27,000 \times g$ for $20 \mathrm{~min}$ at $4^{\circ} \mathrm{C}$. The pellet was rinsed twice, dissolved with $0.25 \mathrm{ml}$ of Soluene- 350 tissue solubilizer (United Technologies Packard), and transferred to a counting vial, and its radioactivity was measured by scintillation spectrometry after the addition of $10 \mathrm{ml}$ of Lumax, hydrophylic scintillator concentrate (llpen Ltd., Givataim, Israel). The $\left[{ }^{3} \mathrm{H}\right] \mathrm{NE}$ uptake was $12 \%$ or less in samples incubated at $0^{\circ} \mathrm{C}$ or at $37^{\circ} \mathrm{C}$ in the presence of $1.07 \times 10^{-4} \mathrm{M}$ desmethylimipramine (Snyder et al., 1968).

Protein determination. The concentration of protein was determined by the method of Lowry et al. (1951).

\section{Histochemical methods}

Catecholamine histofluorescence. Rats were anesthetized with pentobarbitol $(50 \mathrm{mg} / \mathrm{kg})$ and processed according to a modified method for cate- cholamine fluorescence induced by glyoxylic acid (de la Torre and Surgeon, 1976).

\section{Results}

Effects of unilateral ganglionectomy on the residual noradrenergic innervation of the pineal gland

Effects on $T H$ activity. Unilateral ganglionectomy resulted in a rapid reduction in $\mathrm{TH}$ activity, within 2 days, to about $50 \%$ of control (Fig. 1). The reduction was followed by a gradual increase to maximal levels of approximately $80 \%$ of control by 10 days postoperative, where the enzyme activity remained for up to 52 days (Fig. 1).

Effects on $\left[{ }^{3} \mathrm{H}\right.$ ]norepinephrine uptake. Unilateral ganglionectomy resulted in a transient decrease in NE uptake with a time course similar to the one observed for $\mathrm{TH}$ activity (Fig. 1). After a rapid fall within 2 days to about $50 \%$ of control, NE uptake gradually increased to approximately $80 \%$ of control by the 10 th postoperative day, where it remained for up to 28 days (Fig. 1).

No change in protein concentrations was observed in the partially denervated pineal gland (Fig. 1).

Effects on NE histofluorescence. Examination of sections of the pineal gland, processed for catecholamine histofluorescence, at 2 days after unilateral ganglionectomy revealed a major qualitative reduction in both intensity and density of sympathetic terminals throughout the whole pineal gland (Fig. 2, $A$ and $B$ ). By 7 days postoperative, fluorescence intensily and densily were increased, but to levels lower than control (Fig. 2, $A$ and $C$ ). No change in the distribution of fluorescent fibers was observed.

Bilateral ganglionectomy resulted 10 days later in a complete disappearance of fluorescent noradrenergic axon terminals from the pineal gland (Fig. 2D).

\section{Effects of unilateral ganglionectomy on the contralateral SCG}

Effects on CAT activity. Unilateral ganglionectomy resulted in an early transient elevation of CAT activity (Fig. 3). The enzyme activity was increased to about $115 \%$ of control by 4 days; remained at this level for up to 10 days and, by 14 days postoperative, returned to control levels.

Effects on TH activity. A sustained elevation in TH activity was observed in the contralateral SCG following unilateral ganglionectomy (Fig. 3). The enzyme activity was gradually increased to about $145 \%$ of control by 10 days and remained at this level for up to 52 days.

Effects on protein content. General protein content was transiently elevated in the contralateral SCG following unilateral ganglionectomy (Fig. 3), in parallel to changes in CAT activity. Protein content was increased to about $112 \%$ of control by 4 days, remained elevated

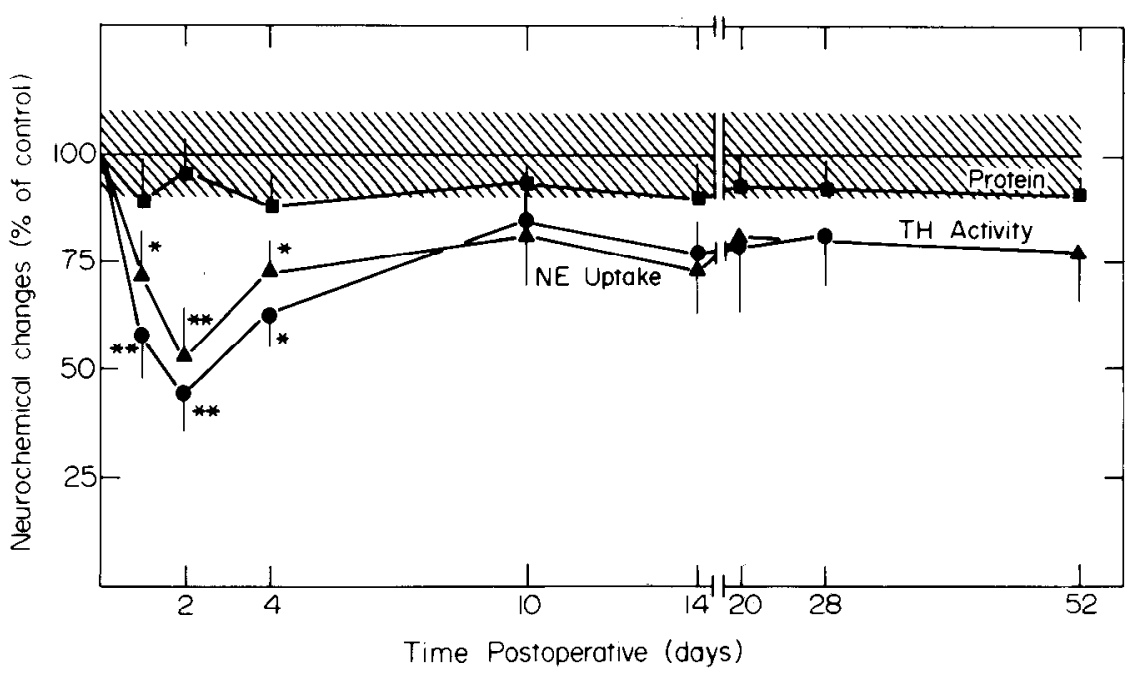

Figure 1. Changes in TH activity $(\boldsymbol{\bullet})$, NE uptake $(\mathbf{\Delta})$, and protein content $(\boldsymbol{\square})$ in the pineal gland following unilateral ganglionectomy. The results ( \pm S.E.M.), values of eight to 10 animals, are expressed as a percentage of unoperated controls (shaded area). * $p<0.05 ; * *, p$ $<0.005$. Note the interruption of the abscissa. The control values were: $\mathrm{TH}=1.4 \pm 0.2 \mathrm{pmol} / \mathrm{pineal} / \mathrm{hr} ; \mathrm{NE}$ uptake $=617 \pm 55 \mathrm{fmol} /$ pineal $/ 10 \mathrm{~min}$; protein content $=191 \pm 13 \mu \mathrm{g} /$ pineal. 

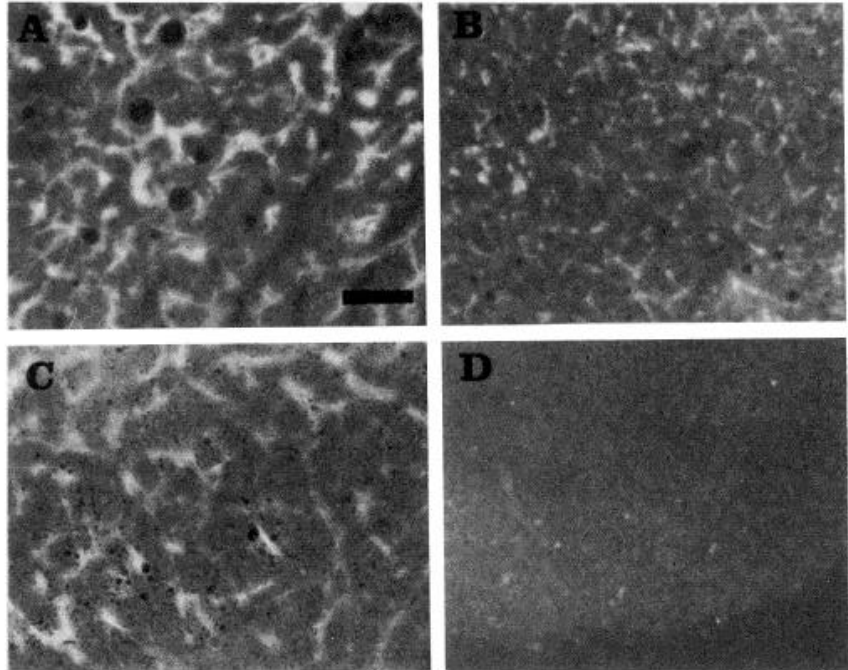

Figure 2. Photomicrographs of catecholamine-induced histofluorescence in sections from the pineal gland of: $A$, unoperated animals; $B$, animals 2 days after unilateral ganglionectomy; $C$, animals 7 days after unilateral ganglionectomy; and $D$, animals 10 days after bilateral ganglionectomy. $B a r$ $=50 \mu \mathrm{m}$.

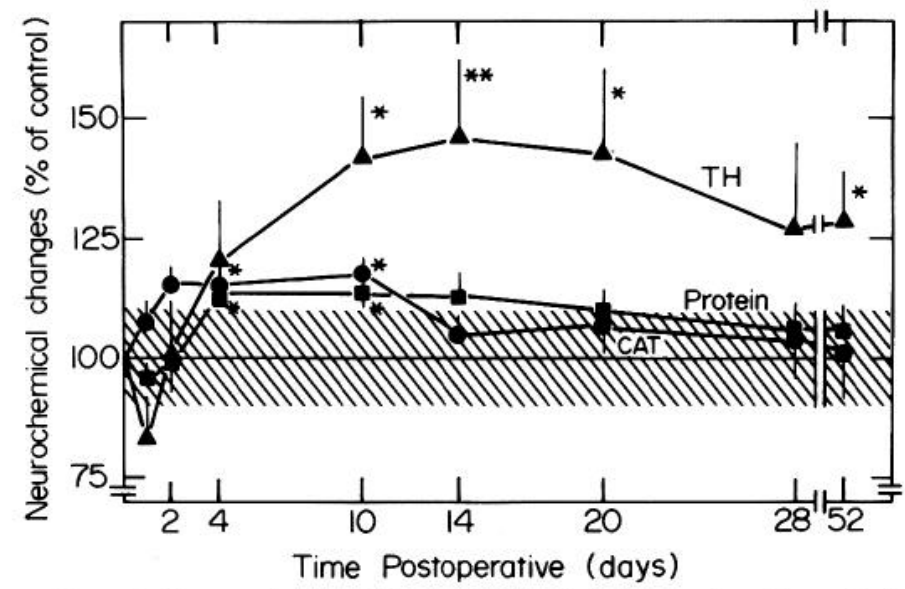

Figure 3. Changes in TH activity $(\bullet)$, CAT activity $(\boldsymbol{\Delta})$, and protein content $(\boldsymbol{\square})$ in the contralateral SCG following unilateral ganglionectomy. The results, mean ( \pm S.E.M.) values of eight to 10 animals, are expressed as a percentage of unoperated controls (shaded area). $*, p<0.05 ; * *, p<0.005$. Note the interruption of the ordinates. The control values were: $\mathrm{TH}=1.6 \pm 0.2 \mathrm{nmol} /$ $\mathrm{SCG} / \mathrm{hr} ; \mathrm{CAT}=106 \pm 6 \mathrm{nmol} / \mathrm{SCG} / \mathrm{hr}$; protein content $=200 \pm 10 \mu \mathrm{g} /$ SCG.

for up to 10 days, and returned to control levels by 14 days postoperative.

\section{Effects of unilateral ganglionectomy combined with decentralization of the contralateral SCG}

Ipsilateral decentralization of the intact SCG just prior (within 5 $\mathrm{min}$ ) to contralateral ganglionectomy prevented the compensatory increase in NE uptake which was observed in the pineal after ganglionectomy alone (Fig. 4). Unilateral decentralization by itself did not result in a significant decrease in NE uptake.

\section{Discussion}

Compensatory homotypic collateral sprouting of noradrenergic axon terminals. The present study indicates that, following unilateral ganglionectomy in adult rat, the remaining noradrenergic axon terminals in the pineal gland which originate from sympathetic neurons in the intact SCG will undergo collateral sprouting. Three lines of evidence support this conclusion: (1) ganglionectomy results in a

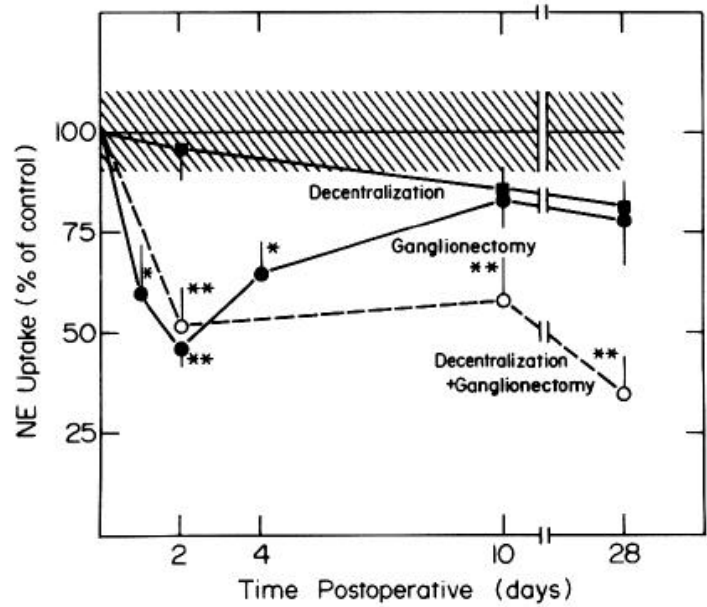

Figure 4. Changes in NE uptake in the pineal gland following unilateral ganglionectomy (ganglionectomy), unilateral decentralization (decentralization), and unilateral ganglionectomy combined with contralateral decentralization (for further explanation, see "Surgery"). The results, mean ( \pm S.E.M.) values of five animals, are expressed as a percentage of unoperated controls (shaded area). $*, p<0.05 ; * *, p<0.005$. The control values of NE uptake were $650 \pm 60 \mathrm{fmol} /$ pineal $/ 10 \mathrm{~min}$.

reduction in the activity of $\mathrm{TH}$ which is followed by a partial but permanent increase in the enzyme activity; (2) similarly, the uptake of $\left[{ }^{3} \mathrm{H}\right] \mathrm{NE}$ into homogenates of the pineal gland is characterized by a transient reduction, followed by a partial but permanent increase; and (3) as demonstrated by catecholamine-induced histofluorescence, the density of NE-containing fibers is first decreased throughout the pineal gland but, after a week, it is partially reinstated. While processes other than sprouting might account singly for each of these changes, this is the best interpretation of the composite.

The development of collateral sprouts from residual noradrenergic terminals in the pineal gland appears closely related, spatially and temporally, to degeneration of the lesioned axon terminals. The hypothetical sequence of these events is schematically depicted in Figure 5. As others have shown (Morgan and Hansen, 1978), within $24 \mathrm{hr}$ after bilateral ganglionectomy, all NE-containing fibers in the pineal gland disappear. In agreement, our data demonstrate that, by 2 days after unilateral ganglionectomy, there is a major reduction in both intensity and density of NE-containing fluorescence fibers. Importantly, the reduction in fluorescent fibers occurs throughout the pineal gland, thus demonstrating that the noradrenergic sympathetic innervation which originates from both the right and left SCGs have a similar distribution within this midline-situated gland. It appears, therefore, that collateral sprouting of intact noradrenergic axon terminals starts only after the degeneration of adjacent terminals, and once the sprouts reach a maximum, they remain in place (Fig. 5). The beginning of increase in both $\mathrm{TH}$ activity and $\left[{ }^{3} \mathrm{H}\right] \mathrm{NE}$ uptake can be observed in the pineal as early as 4 days after ganglionectomy. A comparable time course of events has been previously observed when heterotypic collateral sprouting of central dopaminergic terminal axons took place in the olfactory tubercle in response to its partial denervation after olfactory bulb removal (Gilad and Reis, 1979).

The nature and the source of the signal elicited by ganglionectomy to initiate these compensatory changes in residual noradrenergic terminals is obscure. Stimulating factors (Brown and Holland, 1979; Pockett and Slack, 1982) as well as inhibiting factors (Diamond et al., 1976) which originate from the target tissue have been postulated. In the target tissue, such factors may originate from various cellular elements, such as the degenerating terminals, the deafferented pinealocytes, or Schwann cells (Brown, 1984). Our data indicate, however, that regardless of the nature and the source of the primary signal, the presence of preganglionic innervation of the reactive sympathetic neurons in the SCG is essential for the com- 


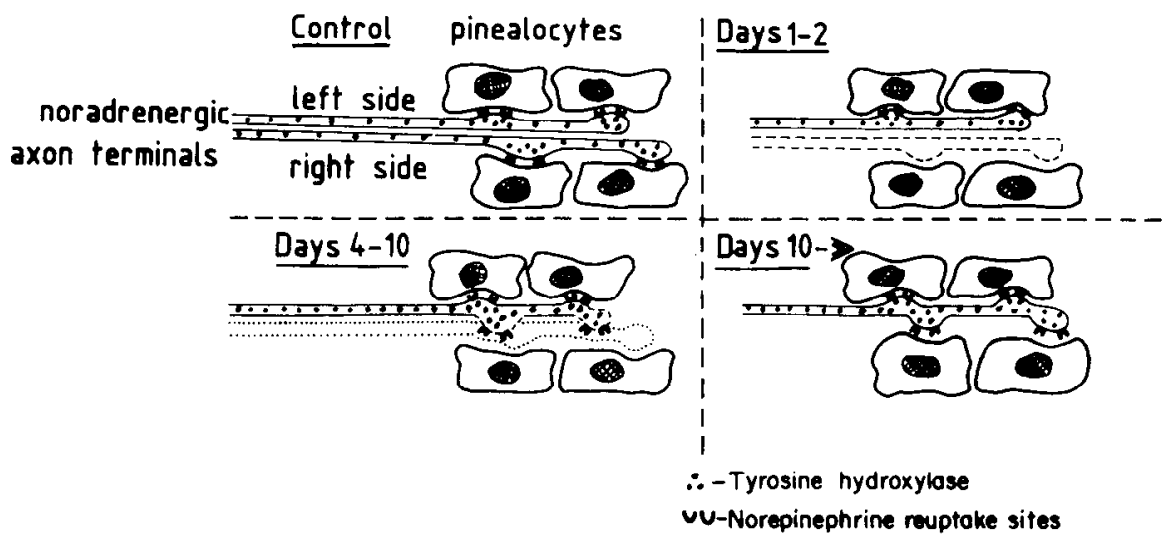

Figure 5. Schematic representation of proposed association of compensatory changes in TH activity and NE uptake with collateral sprouting of residual terminals of sympathetic neurons innervating the pineal gland. Control depicts right and left noradre nergic axon terminals, with similar arborization, innervating the target cells. By days 1 to 2 following unilateral ganglionectomy, the corresponding terminals degenerate. By days 4 to $10, \mathrm{TH}$ activity and NE uptake are increased in the expanding residual terminals. After day 10, new collateral sprouts of the residual noradrenergic terminals are present, with increased TH activity and NE uptake. See text for further discussion.

pensatory collateral sprouting of their terminals in the pineal gland (as adjudged by the sustained increase of $\left[{ }^{3} \mathrm{H}\right] \mathrm{NE}$ uptake). In a model of heterotypic collateral sprouting, Crutcher et al. (1979) showed that afferent input to the SCG is unnecessary for sprouting to occur. The discrepancy in the results may arise from methodological differences, as these authors have performed the decentralization a day before partial denervation of the target tissue, while we have done the two lesions simultaneously. An alternative explanation may be that the preganglionic input is esential for homotypic collat eral sprouting and less so for heterotypic sprouting.

Effects of unilateral ganglionectomy on the contralateral SCG. Unilateral ganglionectomy results in a sympathetic denervation of al the target tissues on the ipsilateral side and leads to compensatory changes in the contralateral SCG. A small and transient increase in CAT activity, evident by 4 days and lasting for 7 days is the first change observed. This is followed by a gradual but sustained increase in $\mathrm{TH}$ activity. Interestingly, a small and transient increase in general protein content of the contralateral SCG occurs in paralle to the change in CAT activity. The cellular localization of this elevation in protein content is uncertain, but if one can draw an analogy from the developmental study of Soinila and Eränkö (1983), such an increase may occur both in principal neurons and in their satellite cells as a result of a sustained increase in neurotransmission activity coupled to metabolic activity in the contralateral ganglion.

In a preliminary study, we observed that unilateral postganglionic cut of the internal carotid nerve, which also resulted in compensatory collateral sprouting of contralateral sympathetic terminals in the pineal gland, fail to enhance CAT or TH activities in the contralateral SCG (data not shown). One explanation for this observation may lie in the sensitivity of our enzyme assays, which could be too low to detect small changes against a relatively high background level of enzyme activities. Alternatively, the changes observed in the SCG after unilateral ganglionectomy may not necessarily be related to the collateral sprouting of terminals in the pineal gland, but may reflect a general enhanced compensatory activity of the contralateral cervical sympathetic system. It has been demonstrated that direct electrical stimulation of the preganglionic input to the SCG which lasts 90 min can produce an increase in $\mathrm{TH}$ activity of the ganglion which lasts about 4 days (Zigmond et al, 1980). Therefore it is not unreasonable to assume that the increase in neurotransmitter-synthesizing enzyme activities observed in the present study is the result of a long-lasting increase in impulse activity in the contralateral sympathetic system. Yet, an even smalier or briefer increase in electrical activity, which might not necessarily result in increased neurotransmitter enzyme activities, may be beneficial for the growth of collateral sprouts (Maehlen and Njå, 1982).

Functional implications. It remains to be established whether the new collateral sprouts of noradrenergic terminals in the pineal gland are functional. Sympathetic neurons of the SCG are essential for the regulation of melatonin biosynthesis in the pineal gland. The influence of these neurons is most evident on the regulation of both the activity and circadian rhythm of the enzyme serotonine $\mathrm{N}$-acetyltransferase (NATase) (Zigmond et al., 1981). It was demonstrated (Zigmond et al., 1981) that a normal NATase activity and rhythm reappeared within $32 \mathrm{hr}$ after unilateral ganglionectomy but, after unilateral decentralization of the SCG, NATase activity remained reduced. These authors hypothesized that, after ganglionectomy, loss of NE uptake sites in the degenerating injured terminals may result in an enhanced effectiveness of the NE released by the residual intact terminals. After decentralization of the SCG, however, uptake sites will remain intact, and therefore recovery does not occur. Our data substantiates this hypothesis and demonstrates that the structural basis for this functional interrelationship between the bilateral noradrenergic innervation of the pineal is the apparent close topographical proximity of their terminals (Fig. 2).

The results of Zigmond et al. (1981) illustrate that a rapid recovery of NATase activity may occur without the need for collateral sprouting to occur. However, preliminary results of experiments carried out in collaboration with Prof. Eitan Friedman (Department of Psychiatry, New York University Medical Center) indicate that melatonin levels in the pineal gland did not completely recover by 7 days after unilateral ganglionectomy. These results may indicate that the activity of the melatonin-synthesizing enzyme, hydroxyindole O-methyitransferase, did not yet return to its preoperative levels by 7 days and that its complete recovery awaits the maturation of compensatory collateral sprouts (as indicated by the elevation in $\left[{ }^{3} \mathrm{H}\right] \mathrm{NE}$ uptake and TH activity). These studies and others (Zigmond et al., 1985, in press) indicate that maximal recovery of function of a target tissue after subtotal degeneration of one of its afferents, due to injury or disease, may be the result of a combination of two mechanisms occurring in sequence. The first one, which occurs earlier (within 2 days), is due to the net increase in the amount of neurotransmitter released from residual terminals secondary to the loss of uptakc site, on the degenerated terminals (Zigmond et al., 1981; Zigmond et al., 1985, in press). The second one is the enlargement of the terminal arborization by collateral sprouting of residual terminals, a process which requires about 10 days to occur, as indicated by the present study.

\section{References}

Brown, M. C. (1984) Sprouting of motor nerves in adult muscles: A recapitulation of ontogeny. Trends Neurosci. 7: 10-14.

Brown, M. C., and R. L. Holland (1979) A central role for denervated tissues in causing nerve sprouting. Nature 282: 724-726.

Coyle, J. T. (1972) Tyrosine hydroxylase in rat brain-cofactor requirements, regional and subcellular distribution. Biochem. Pharmacol. 21: 1935-1944.

Crutcher, K. A., L. Brothers, and J. N. Davis (1979) Sprouting of sympathetic nerves in the absence of afferent input. Exp. Neurol. 66: 778-783.

de la Torre, J. C., and J. W. Surgeon (1976) A methodological approach to rapid and sensitive monoamine histofluorescence using a modified glyoxylic acid technique: The SPG method. Histochemistry 49: 81-93.

Diamond, J., E. Cooper, C. Turner, and L. Macintyre (1976) Trophic regulation of nevve sprouting. Science 193: 371-377. 
Edds, M. V. (1953) Collateral nerve regeneration. Quart. Rev. Biol. 28: 260276.

Fonnum, F. (1969) Radiochemical micro assays for the determination of choline acetyltransferase and acetylcholinesterase activities. Biochem. J. 115: 465-472.

Gilad, G. M., and V. H. Gilad (1983) Sequential biochemical alterations in sympathetic neurons following axonal injuries. In Nervous System Regeneration, B. Haber, J. R. Perez-Polo, and A. M. Giuffrida Stalla, eds., pp. 437-444, Alan R. Liss, Inc., New York.

Gilad, G. M., and I. J. Kopin (1979) Neurochemical aspects of neuronal ontogenesis in the developing rat cerebellum: Changes in neurotransmitter and polyamine synthesizing enzymes. J. Neurochem. 33: 1195-1204.

Gilad, G. M., and D. J. Reis (1979) Collateral sprouting in central mesolimbic dopamine neurons: Biochemical and immunocytochemical evidence of changes in the activity and distribution of tyrosine hydroxylase in terminal fields and in cell bodies of A10 neurons. Brain Res. 160: 17-36.

Gilad, G. M., C. Gagnon, and I. J. Kopin (1980) Protein carboxymethylase activity in the rat superior cervical ganglion during development and after axonal injury. Brain Res. 183: 393-402.

Guth, L., and J. J. Bernstein (1961) Selectivity in the re-establishment of synapses in the superior cervical sympathetic ganglion of the cat. Exp. Neurol. 4: 59-69.

Heikkila, R. E., H. Orlowsky, C. Mytilineou, and G. Cohen (1975) Amphetamine: evaluation of $d$ - and $/$-isomers as releasing agents and uptake inhibitors for ${ }^{3} \mathrm{H}$-dopamine and ${ }^{3} \mathrm{H}$-norepinephrine in slices of rat neostriatum and cerebral cortex. J. Pharmacol. Exp. Ther. 194: 47-56.

Kappers, J. A. (1960) The development, topographical relations and innervation of the epiphysis cerebri in the albino rat. Z. Zellforsch. 52: 163215.

Kobayashi, R. M., M. Brownstein, J. M. Saavedra and M. Palkovits (1975) Choline acetyltransferase content in discrete regions of the rat brain stem. J. Neurochem. 24: 637-640.
Lowry, O. H., N. J. Rosebrough, A. L. Farr, and R. J. Randall (1951) Protein measurement with the folin phenol reagent. J. Biol. Chem. 193: 265-275.

Loy, R., and R. Y. Moore (1977) Anomalous innervation of the hippocampal formation by peripheral sympathetic axons following mechanical injury. Exp. Neurol. 57: 645-650.

Maehlen, J., and A. Niå (1982) The effects of electrical stimulation on sprouliriy afler parlial denervation of Guinea pig sympathetic ganglion cells. J. Physiol. 322: 151-166.

Morgan, W. W., and J. T. Hansen (1978) Time course of the disappearance of pineal noradrenaline following superior cervical ganglionectomy. Exp. Brain Res. 32: 429-434.

Pockett, S., and J. R. Slack (1982) Source of the stimulus for nerve terminal sprouting in partially denervated muscle. Neuroscience $7: 3173-3176$.

Soinila, S., and O. Eränkö (1983) Increase in the number of non-neuronal cells in superior cervical ganglia of developing rats after contralateral ganglionectomy. Neuroscience 9: 911-915.

Stenevi, U., and A. Björklund (1978) Growth of vascular sympathetic axons into the hippocampus after lesions of the septohippocampal pathway: A pitfall in brain lesion studies. Neurosci. Lett. 7: 219-224.

Zieher, L. M., and A. Pellagrino de Iraldi (1966) Central control of the noradrenaline content in the rat pineal and submaxillary gland. Life Sci. 5: $155-161$.

Zigmond, R. E., C. Baldwin, and C. W. Bowers (1981) Rapid recovery of function after partial denervation of the rat pineal gland suggests a novel mechanism for neural plasticity. Proc. Natl. Acad. Sci. U. S. A. 78: 39593963.

Zigmond, M. J., T. W. Berger, and E. M. Stricker (1985) Biochemical anatomical and electrophysiological analyses of behavioral sparing after injury of dopaminergic projections in the rat. In Recovery from Neural Trauma, G. M. Gilad, A. Gorio, and G. Kreutzberg, eds., Springer, Berlin, in press.

Zigmond, R. E., A. Chalazonitis, and T. Joh (1980) Preganglionic nerve stimulation increases the amount of tyrosine hydroxylase in the rat superior cervical ganglion. Neurosci. Lett. 20: 61-65. 